\title{
Impact of Physical Activity on Cardiovascular Events in Patients With Chronic Heart Failure
} - A Multicenter Prospective Cohort Study -

\author{
Yutaka Miura, MD, PhD; Yoshihiro Fukumoto, MD, PhD; Toshiro Miura, MD, PhD; \\ Kazunori Shimada, MD; Masanori Asakura, MD, PhD; Toshiaki Kadokami, MD, PhD; \\ Shin-ichi Ando, MD, PhD; Satoshi Miyata, PhD; Yasuhiko Sakata, MD, PhD; \\ Hiroyuki Daida, MD; Masunori Matsuzaki, MD, PhD; Satoshi Yasuda, MD, PhD; \\ Masafumi Kitakaze, MD, PhD; Hiroaki Shimokawa, MD, PhD
}

\begin{abstract}
Background: We have previously demonstrated that the prevalence of metabolic syndrome in chronic heart failure $(\mathrm{CHF})$ is more than double compared with the general population in Japan. However, the impact of physical activity on cardiovascular events in CHF patients remains to be fully elucidated.
\end{abstract}

\begin{abstract}
Methods and Results: We performed a prospective, nationwide large-scale multicenter study of 9,178 patients with stage $A / B / C / D$ CHF in Japan. We obtained the baseline physical activity data for 7,292 and yearly changes in physical activity data during a 3-year follow-up period for 4,353 patients. We divided the patients into high- and lowexercise groups by using the median value of physical activity in the stage $A / B$ and $C / D$ groups. In both groups, patients who exercised more were characterized by younger age and less advanced stage of $\mathrm{CHF}$. Importantly, the baseline physical activity levels were significantly associated with all-cause death, heart failure (HF) hospitalization and other cardiovascular events (except acute myocardial infarction, stroke, HF hospitalization). Furthermore, the yearly change in physical activity level was also significantly associated with HF hospitalization and other cardiovascular events in both groups.
\end{abstract}

Conclusions: The baseline level of physical activity and its yearly changes are significantly associated with all-cause death and major cardiovascular events in both stage $A / B$ and $C / D$ patients, suggesting that physical activity could be an important therapeutic target to improve the long-term prognosis of CHF patients. (Circ J 2013; 77: 2963-2972)

Key Words: Chronic heart failure; Heart failure hospitalization; Physical activity; Prognosis

$\mathbf{T}$ he prevalence of lifestyle diseases, such as diabetes mellitus, dyslipidemia, hypertension, and their combination in metabolic syndrome (MetS), has been rapidly increasing in Japan over the past decades, because of westernization of lifestyle. ${ }^{1}$ Recently, we performed a prospective, nationwide large-scale multicenter study supported by the Japanese government on the current status of chronic heart failure (CHF) patients in Japan, with a special reference to lifestyle diseases, and demonstrated that the prevalence of MetS in CHF patients is more than double compared with the general population in Japan. ${ }^{2}$ This suggests that lifestyle diseases have a substantial impact on the development of both ischemic and non-ischemic $\mathrm{CHF}^{2,3}$

$\mathrm{CHF}$ is a complex clinical syndrome in which both $\mathrm{HF}$ with preserved ejection fraction (HFpEF) and $\mathrm{HF}$ with reduced $\mathrm{EF}$ (HFrEF) are substantially involved. ${ }^{3-7}$ We have also demonstrated that the prevalence of the metabolic components is comparable between HFpEF and HFrEF. ${ }^{2}$ In Japan, CHF has become a growing social issue as the number of $\mathrm{CHF}$ patients has been rapidly increasing because of the aging of the popu-

Received June 17, 2013; revised manuscript received August 4, 2013; accepted August 19, 2013; released online September 27, 2013 Time for primary review: 11 days

Department of Cardiovascular Medicine, Tohoku University Graduate School of Medicine, Sendai (Y.M., Y.F., S.M., Y.S., H.S.); Division of Cardiology, Department of Medicine and Clinical Science, Yamaguchi University Graduate School of Medicine, Ube (T.M., M.M.); Department of Cardiovascular Medicine, Juntendo University School of Medicine, Tokyo (K.S., H.D.); Cardiovascular Division of Internal Medicine, National Cerebral and Cardiovascular Center, Suita (M.A., S.Y., M.K.); and Division of Cardiovascular Medicine, Saiseikai Futsukaichi Hospital, Chikushino (T.K., S.A.), Japan

The Guest Editor for this article was Hiroshi Ito, MD.

Mailing address: Hiroaki Shimokawa, MD, PhD, Professor and Chairman, Department of Cardiovascular Medicine, Tohoku University Graduate School of Medicine, 1-1 Seiryo-machi, Aoba-ku, Sendai 980-8574, Japan. E-mail: shimo@ cardio.med.tohoku.ac.jp

ISSN-1346-9843 doi:10.1253/circj.CJ-13-0746

All rights are reserved to the Japanese Circulation Society. For permissions, please e-mail: cj@j-circ.or.jp 


\begin{tabular}{|c|c|c|c|c|c|c|}
\hline & \multicolumn{3}{|c|}{ Stage $A / B(n=4,435)$} & \multicolumn{3}{|c|}{ Stage $C / D(n=2,857)$} \\
\hline & $\begin{array}{l}\text { Low-Ex } \\
(n=2,097)\end{array}$ & $\begin{array}{c}\text { High-Ex } \\
(n=2,338)\end{array}$ & $P$ value & $\begin{array}{l}\text { Low-Ex } \\
(n=1,525)\end{array}$ & $\begin{array}{c}\text { High-Ex } \\
(n=1,332)\end{array}$ & $P$ value \\
\hline Age (years) & $69.1 \pm 0.3$ & $66.7 \pm 0.2$ & $<0.001$ & $69.5 \pm 0.3$ & $66.4 \pm 0.3$ & $<0.001$ \\
\hline Sex (male) & $1,498(71.4 \%)$ & $1,641(70.2 \%)$ & NS & $1,032(67.7 \%)$ & 925 (69.4\%) & NS \\
\hline Cigarette smoking, n (\%) & & & NS & & & NS \\
\hline Never & $985(66.7 \%)$ & $1,136(68.1 \%)$ & & $755(68.2 \%)$ & $693(69.8 \%)$ & \\
\hline Former & $119(8.1 \%)$ & $144(8.6 \%)$ & & $87(7.9 \%)$ & $70(7.0 \%)$ & \\
\hline Current & $372(25.2 \%)$ & $387(23.2 \%)$ & & 265 (23.9\%) & $230(23.2 \%)$ & \\
\hline Alcohol intake, n (\%) & & & NS & & & 0.001 \\
\hline Never & $928(49.0 \%)$ & $1,010(47.8 \%)$ & & $648(47.1 \%)$ & $644(52.7 \%)$ & \\
\hline Former & $136(7.2 \%)$ & $178(8.4 \%)$ & & $118(8.6 \%)$ & $65(5.3 \%)$ & \\
\hline Current & $831(43.9 \%)$ & $926(43.8 \%)$ & & $611(44.4 \%)$ & $512(41.9 \%)$ & \\
\hline BMI $\left(\mathrm{kg} / \mathrm{m}^{2}\right)$ & $24.0 \pm 0.8$ & $24.0 \pm 0.8$ & NS & $24.1 \pm 0.1$ & $24.2 \pm 0.1$ & NS \\
\hline Waist $(\mathrm{cm})$ & $86.0 \pm 0.2$ & $86.1 \pm 0.2$ & NS & $86.0 \pm 0.3$ & $86.5 \pm 0.3$ & NS \\
\hline \multicolumn{7}{|l|}{ Blood pressure $(\mathrm{mmHg})$} \\
\hline Systolic & $128.5 \pm 0.4$ & $128.5 \pm 0.4$ & NS & $128.0 \pm 0.5$ & $128.9 \pm 0.5$ & NS \\
\hline Diastolic & $73.5 \pm 0.3$ & $73.8 \pm 0.2$ & NS & $73.5 \pm 0.3$ & $73.6 \pm 0.3$ & NS \\
\hline Heart rate (beats/min) & $70.4 \pm 0.3$ & $70.3 \pm 0.3$ & NS & $70.9 \pm 0.4$ & $71.3 \pm 0.4$ & NS \\
\hline \multicolumn{7}{|l|}{ NYHA } \\
\hline III/IV & - & - & - & 99 (6.5\%) & $70(5.3 \%)$ & NS \\
\hline $\mathrm{EF}(\%)$ & $61.8 \pm 0.3$ & $62.4 \pm 0.3$ & NS & $61.3 \pm 0.4$ & $61.2 \pm 0.4$ & NS \\
\hline HFpEF (EF $\geq 50 \%)$ & $1,616(81.9 \%)$ & $1,826(82.6 \%)$ & NS & $1,159(79.6 \%)$ & $1,007(79.2 \%)$ & NS \\
\hline $\mathrm{HT}$ & $1,589(76.1 \%)$ & $1,803(77.3 \%)$ & NS & $1,208(79.4 \%)$ & $1,041(78.5 \%)$ & NS \\
\hline DM or fasting glucose $\geq 110 \mathrm{mg} / \mathrm{dl}$ & $515(24.8 \%)$ & $580(24.9 \%)$ & NS & $423(27.9 \%)$ & $330(24.9 \%)$ & NS \\
\hline Dyslipidemia & $1,513(72.6 \%)$ & $1,692(72.5 \%)$ & NS & $1,145(75.2 \%)$ & $979(73.9 \%)$ & NS \\
\hline Serum creatinine $\geq 3.0 \mathrm{mg} / \mathrm{dl}$ & $33(1.6 \%)$ & $38(1.6 \%)$ & NS & $31(2.0 \%)$ & $27(2.0 \%)$ & NS \\
\hline Hemodialysis & $23(1.1 \%)$ & $24(1.0 \%)$ & NS & $16(1.1 \%)$ & $19(1.4 \%)$ & NS \\
\hline IHD & $1,124(53.6 \%)$ & $1,201(51.4 \%)$ & NS & 785 (51.5\%) & $708(53.2 \%)$ & NS \\
\hline HHD & $217(10.3 \%)$ & $284(12.1 \%)$ & NS & $153(10.0 \%)$ & $144(10.8 \%)$ & NS \\
\hline $\mathrm{CM}$ & 257 (12.3\%) & 281 (12.0\%) & NS & 221 (14.5\%) & 179 (13.4\%) & NS \\
\hline VHD & 406 (19.4\%) & $474(20.3 \%)$ & NS & 299 (19.6\%) & $274(20.6 \%)$ & NS \\
\hline $\mathrm{CHD}$ & $31(1.5 \%)$ & $42(1.8 \%)$ & NS & $27(1.8 \%)$ & $22(1.7 \%)$ & NS \\
\hline BNP & $127.0 \pm 4.1$ & $131.9 \pm 5.1$ & NS & $140.3 \pm 5.6$ & $155.6 \pm 9.0$ & NS \\
\hline Exercise & $2.0 \pm 0.03$ & $14.3 \pm 0.2$ & $<0.001$ & $1.7 \pm 0.03$ & $14.2 \pm 0.3$ & $<0.001$ \\
\hline \multicolumn{7}{|l|}{ Medications } \\
\hline ACEI/ARB & $1,261(60.1 \%)$ & $1,348(57.7 \%)$ & NS & 1,097 (71.9\%) & $957(71.8 \%)$ & NS \\
\hline$\beta$-blocker & 776 (37.0\%) & 759 (32.5\%) & $<0.01$ & 783 (51.3\%) & $679(51.0 \%)$ & NS \\
\hline Statin & 988 (47.1\%) & $1,120(47.9 \%)$ & NS & $616(40.4 \%)$ & $568(42.6 \%)$ & NS \\
\hline
\end{tabular}

Results are expressed as mean \pm SEM.

ACEI, angiotensin-converting enzyme inhibitor; ARB, angiotensin-receptor blocker; BMI, body mass index; BNP, brain natriuretic peptide; $\mathrm{CHD}$, congenital heart disease; $\mathrm{CHF}$, chronic heart failure; $\mathrm{CM}$, cardiomyopathy; DM, diabetes mellitus; EF, ejection fraction; HFpEF, heart failure with preserved ejection fraction; HHD, hypertensive heart disease; HT, hypertension; IHD, ischemic heart disease; NS, not significant; VHD, valvular heart disease.

lation, ${ }^{3-7}$ so not only westernization of lifestyle but also reduced physical activity may be involved. ${ }^{8}$

Although physical activity is important for improvement lifestyle diseases, its impact on cardiovascular events in CHF remains to be elucidated, especially in terms of yearly changes in physical activity level. Thus, in the present study, we examined whether the baseline level of and yearly changes in physical activity influenced the occurrence of major cardiovascular events in $\mathrm{CHF}$ patients in our multicenter prospective cohort study.

\section{Methods}

The ethics committees of each institute approved the study protocol and all patients provided written informed consent.

\section{Study Population}

In this multicenter study, we prospectively enrolled 9,178 CHF patients in stages A/B/C/D by the ACC/AHA Guidelines ${ }^{9}$ between September 2006 and December 2010 from 5 institutes in Japan. ${ }^{2}$ For each patient, we used an online data collection system (Fujitsu Systems East Limited, Tokyo, Japan) to prospectively collect data from the participating hospitals: baseline demographic data; medications; comorbidities (previous myocardial infarction (MI) or stroke, dialysis, and atrial fibrillation); physical activity; cardiovascular events (acute MI [AMI], stroke, and HF hospitalization), and death.

Physical activity level (Exercise units) was assessed using a shortened version of the Japanese Exercise Guide 2006 published by the Japanese Ministry of Health, Labor, and Welfare 


\begin{tabular}{|c|c|c|c|c|c|c|}
\hline & \multicolumn{3}{|c|}{ Stage A/B $(n=2,756)$} & \multicolumn{3}{|c|}{ Stage $C / D(n=1,597)$} \\
\hline & Baseline & Follow-up & $P$ value & Baseline & Follow-up & $P$ value \\
\hline Male & $5.8,9.4 \pm 0.2$ & $4.3,7.2 \pm 0.2$ & $<0.001$ & $5.0,8.6 \pm 0.3$ & $3.4,6.3 \pm 0.2$ & $<0.001$ \\
\hline Female & $4.9,8.4 \pm 0.3$ & $3.2,5.6 \pm 0.3$ & $<0.001$ & $3.9,7.7 \pm 0.5$ & $2.3,4.9 \pm 0.3$ & $<0.001$ \\
\hline
\end{tabular}

Results are expressed as median, mean \pm SEM. Abbreviation as in Table 1.

(Table S1): 1 Exercise (Ex) equals 1 METS $\times 1 \mathrm{~h}$ (unit of physical activity).$^{10}$ Because of non-normal distribution, we divided the patients in stages $\mathrm{A} / \mathrm{B}$ and $\mathrm{C} / \mathrm{D}$ into high- and low-exercise groups according to the median value of physical activity in each group. Furthermore, we divided the patients into 4 groups, depending on each median of the baseline and followup physical activity levels: "low to low", "low to high", "high to low" and "high to high" groups.

\section{Data Collection}

Data for baseline demographics (age, sex, height, body weight, waist circumference, blood pressure and heart rate), CHF stage, medications (angiotensin-converting enzyme inhibitor [ACEI], angiotensin-receptor blocker [ARB], $\beta$-blocker, and statins), risk factors (hypertension, glucose intolerance/diabetes mellitus and dyslipidemia), biochemical data (lipid profile and glucose), plasma levels of brain natriuretic peptide (BNP), and comorbidities (ischemic heart disease [IHD], clinically diagnosed hypertensive heart disease, cardiomyopathy, valvular heart disease, and congenital heart disease) were based on the medical records. ${ }^{2}$ Left ventricular ejection fraction (LVEF) was measured by echocardiography. ${ }^{2}$

The primary endpoints included all-cause death, AMI, stroke, HF hospitalization, and other cardiovascular events (except AMI, stroke, and HF hospitalization), such as percutaneous coronary intervention for stable effort angina and intervention for peripheral artery disease.

\section{Definition of Metabolic Disorders}

Dyslipidemia was diagnosed by use of lipid-lowering drugs and/or elevated lipid levels defined as low-density lipoprotein $\geq 140 \mathrm{mg} / \mathrm{dl}$, plasma triglycerides $\geq 150 \mathrm{mg} / \mathrm{dl}$ or high-density lipoprotein $<40 \mathrm{mg} / \mathrm{dl}$ in men and $50 \mathrm{mg} / \mathrm{dl}$ in women. Glucose intolerance/diabetes mellitus was diagnosed by use of antidiabetic drugs and/or fasting glucose $\geq 110 \mathrm{mg} / \mathrm{dl}$. Hypertension was diagnosed by use of antihypertensive drugs and/or systolic blood pressure $\geq 130 \mathrm{mmHg}$ and/or diastolic blood pressure $\geq 80 \mathrm{mmHg}$.

\section{Definition of Heart Failure}

According to the ESC 2007 Guidelines, we further divided the patients with stages $\mathrm{A} / \mathrm{B} / \mathrm{C} / \mathrm{D}$ CHF into 2 groups: $\mathrm{HFpEF}$ (LVEF $\geq 50 \%, \mathrm{n}=5,608)$ and $\mathrm{HFrEF}(\mathrm{LVEF}<50 \%, \mathrm{n}=1,684) .{ }^{11}$

\section{Statistical Analysis}

Continuous variables are expressed as means and standard errors of mean (SEM), and categorical variables as counts and percentages. Comparisons between 2 groups were conducted with Welch's t-test for continuous variables and the chi-squared test for categorical variables. Statistical analyses were performed using SPSS (SPSS Inc, Chicago, IL, USA) and the statistical computing software R version 2.15.1 (http://www. r-project.org). $\mathrm{P}<0.05$ was considered to be statistically significant.

\section{Results}

Of the 9,178 consecutive patients with stages $A / B$ and $C / D$ of $\mathrm{CHF}$, we were able to obtain baseline physical activity data for 7,292 (Table S2). There were 3,139 male and 1,296 female patients in stage $\mathrm{A} / \mathrm{B}$, and 1,957 male and 900 female patients in stage C/D (Table 1). Among them, data of the yearly changes in physical activity level during the 3-year follow-up were available for 4,353 patients (Table S3).

\section{Baseline Physical Activity Level}

The median level of physical activity was 8.9 Ex in men and 7.6 Ex in women in stage $\mathrm{A} / \mathrm{B}$, and 8.0 Ex in men and 6.6 Ex in women in stage $\mathrm{C} / \mathrm{D}$ (Table 2). When the patients were divided into high- and low-exercise groups using the median value of physical activity, the high-exercise group was characterized by younger age, earlier stages of $\mathrm{CHF}$, and less likelihood of taking medications such as ACEI/ARB or $\beta$-blocker (Tables 1,S2).

\section{Baseline Physical Activity Level and Cardiovascular Events and Mortality}

In all patients, as well as in both stages $\mathrm{A} / \mathrm{B}$ and $\mathrm{C} / \mathrm{D}$, the prognosis for all-cause death was significantly better in the high-exercise group (Figures $\mathbf{1 A}-\mathrm{C}$ ), especially male patients in stage C/D (Figure 1D). It was also the case for admission for worsening $\mathrm{HF}$ except for female patients with stage $\mathrm{A} / \mathrm{B}$ (Figures 2A-D).

Similarly, regarding other cardiovascular events (except AMI, stroke and HF hospitalization), the prognosis was significantly better in patients in the high-exercise group in both stage $\mathrm{A} / \mathrm{B}$ and $\mathrm{C} / \mathrm{D}$ (Figures $3 \mathrm{~A}-\mathrm{C}$ ). In particular, multivariate analysis showed that a high level of physical activity is an independent prognostic factor for both male and female CHF patients in stages A-D (Figure 3D).

Regarding the occurrence of AMI, the prognosis of stage $\mathrm{C} / \mathrm{D}$ patients was significantly better in the high-exercise group (Figures S1A-C); however, multivariate analyses showed only a significant correlation between baseline physical activity level and AMI in patients in stages A-D (Figure S1D). In stroke, the prognosis of stage $\mathrm{A} / \mathrm{B}$ patients was significantly better in the high-exercise group (Figures S3A-C). Multivariate analyses showed a significant correlation between baseline physical activity level and stroke in stage A/B patients (Figure S3D).

\section{Yearly Change in Physical Activity Level}

During follow-up of $1.4 \pm 0.01$ years, the physical activity level in male patients decreased from $9.4 \pm 0.2$ to $7.2 \pm 0.2 \mathrm{Ex}$ in stage $\mathrm{A} / \mathrm{B}$ and from $8.6 \pm 0.3$ to $6.3 \pm 0.2 \mathrm{Ex}$ in stage $\mathrm{C} / \mathrm{D}$, and that in female patients also decreased from $8.4 \pm 0.3$ to $5.6 \pm 0.3 \mathrm{Ex}$ in stage $\mathrm{A} / \mathrm{B}$ and from $7.7 \pm 0.5$ to $4.9 \pm 0.3 \mathrm{Ex}$ in stage $\mathrm{C} / \mathrm{D}$ (Table 2). In the high-exercise group, a high level of physical activity was maintained in $809(29 \%)$ stage A/B patients 


\section{All-Cause Death}

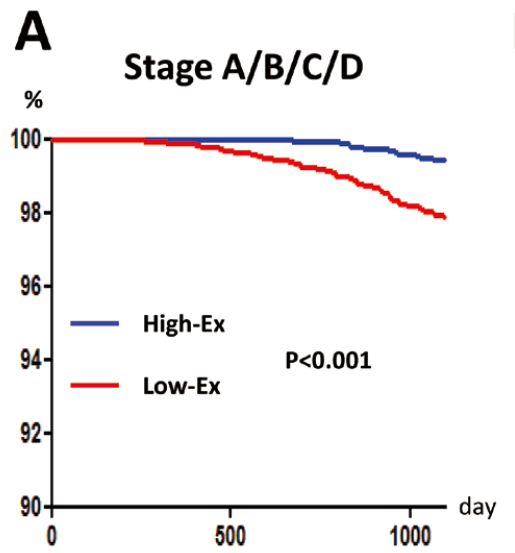

B

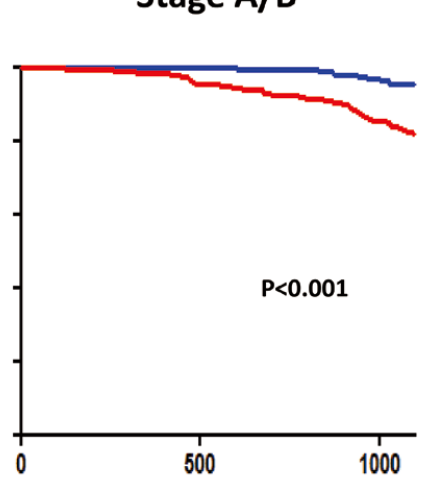

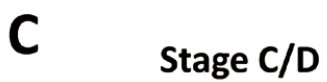

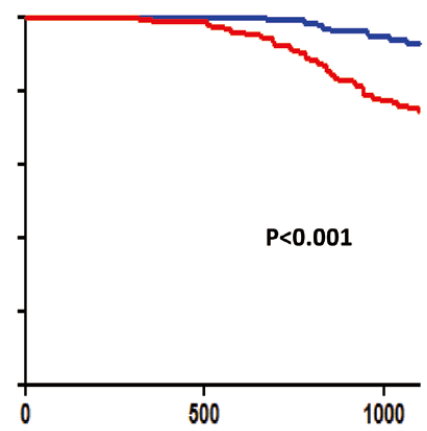

No. at risk

\begin{tabular}{|c|c|c|c|c|c|c|c|c|c|c|c|c|c|c|c|}
\hline High-Ex & 3,670 & 3,670 & 3,670 & 3,666 & 3,189 & 2,338 & 2,338 & 2,338 & 2,337 & 2,011 & 1,332 & 1,332 & 1,332 & 1,329 & 1,178 \\
\hline Low-Ex & 3,622 & 3,621 & 3,610 & 3,587 & 3,148 & 2,097 & 2,096 & 2,088 & 2,077 & 1,804 & 1,525 & 1,525 & 1,523 & 1,511 & 1,344 \\
\hline
\end{tabular}

\section{Kaplan-Meier Estimate}

D

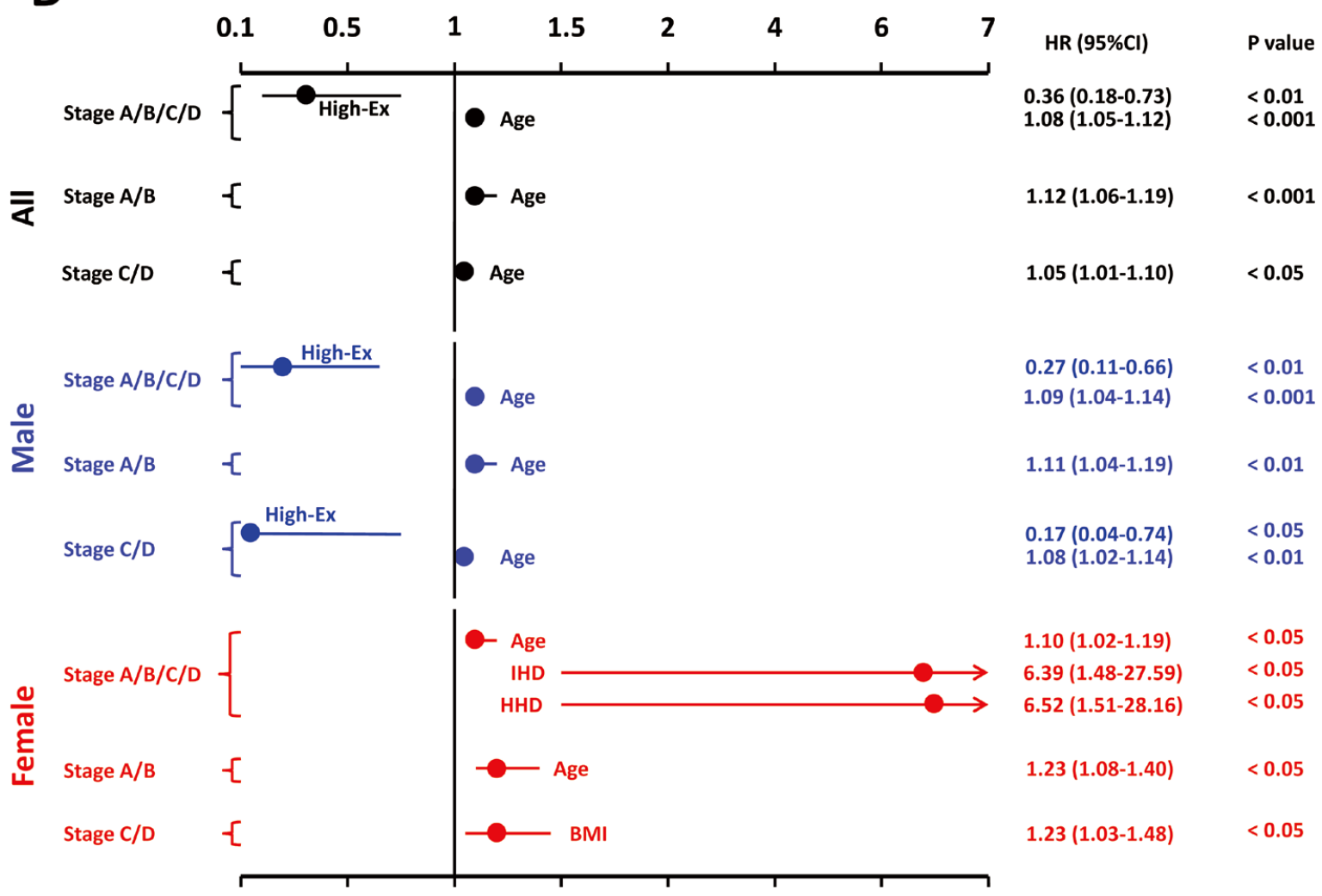

Figure 1. Baseline physical activity level and all-cause death in patients with chronic heart failure. The high-exercise (High-Ex) group showed better prognosis for all-cause death in all patients (A), as well as in stage A/B (B) and stage C/D (C) patients. The prognosis for male patients in stage C/D was significantly associated with a high-exercise level (D). BMI, body mass index; HHD, hypertensive heart disease; IHD, ischemic heart disease. 


\section{HF Hospitalization}

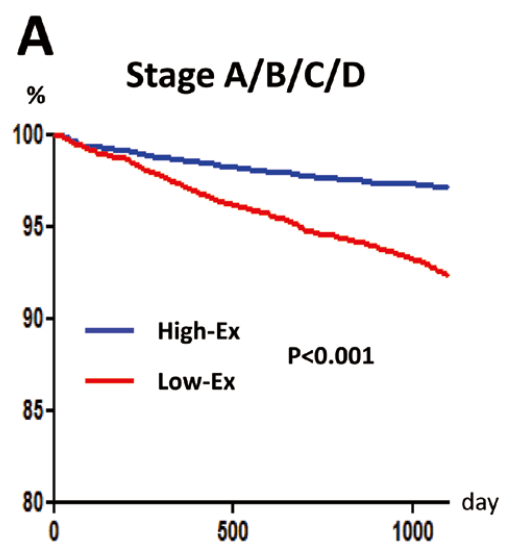

B

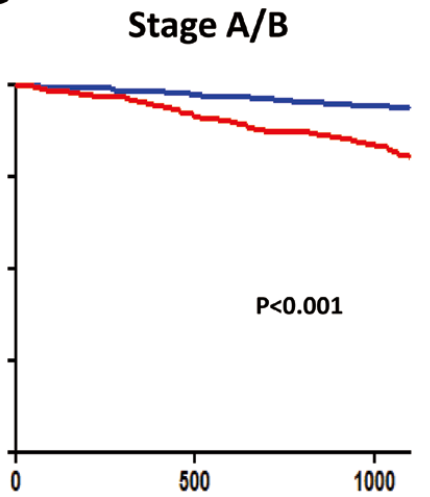

C

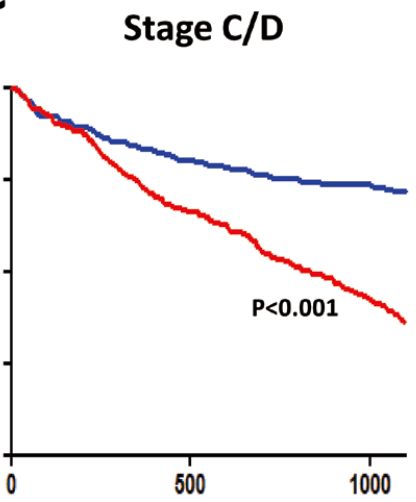

No. at risk

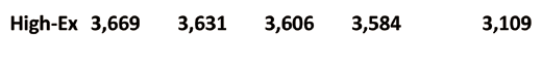

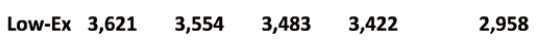

$\begin{array}{rrrrr}2,338 & 2,335 & 2,327 & 2,320 & 1,994 \\ 2,097 & 2,085 & 2,061 & 2,041 & 1,762\end{array}$

$994 \quad 1,331 \quad 1,297 \quad 1,280 \quad 1,265$

$\begin{array}{lllll}1,762 & 1,524 & 1,470 & 1,423 & 1,382\end{array}$

1,115

Kaplan-Meier Estimate

D

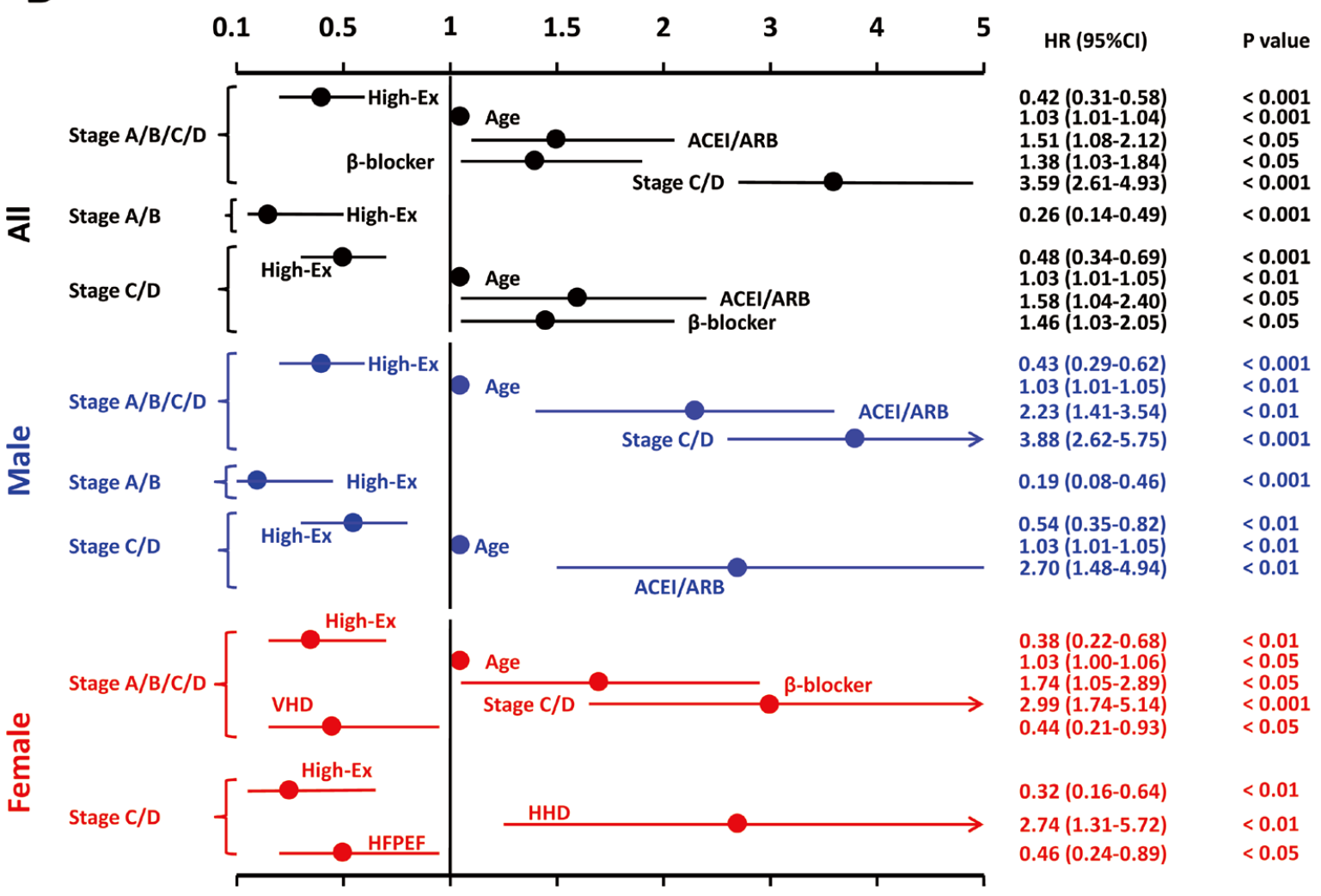

Figure 2. Baseline physical activity level and admission for worsening heart failure (HF). The high-exercise (High-Ex) group showed better prognosis for admission for worsening HF in all patients (A), as well as in stage A/B (B), and stage C/D (C) patients. The better prognosis was significantly associated with high-exercise level except for female patients in stage A/B (D). ACEl, angiotensin-converting enzyme inhibitor; ARB, angiotensin-receptor blocker; HHD, hypertensive heart disease; HFpEF, HF with preserved ejection fraction; VHD, valvular heart disease. 


\section{Other Cardiovascular Events}

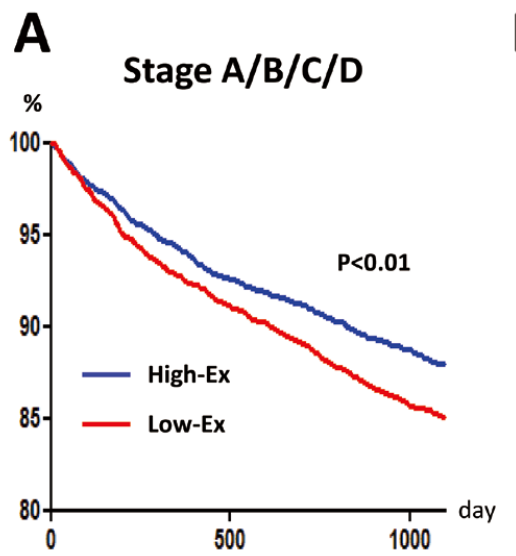

B
Stage A/B

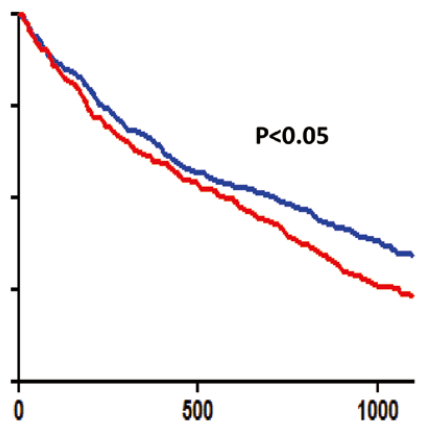

C Stage C/D

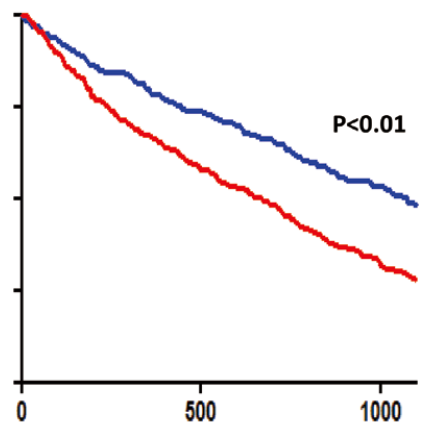

No. at risk

\begin{tabular}{|c|c|c|c|c|c|c|c|c|c|c|c|c|c|c|}
\hline High-Ex 3,661 & 3,668 & 3,500 & 3,391 & 2,818 & 2,332 & 2,212 & 2,131 & 2,092 & 1,756 & 1,329 & 1,289 & 1,260 & 1,229 & 1,062 \\
\hline Low-Ex 3,618 & 3,412 & 3,297 & 3,191 & 2,720 & 2,094 & 1,966 & 1,901 & 1,837 & 1,545 & 1,524 & 1,446 & 1,397 & 1,355 & 175 \\
\hline
\end{tabular}

\section{Kaplan-Meier Estimate}

D Cox Hazard Ratio and 95\% Confidence Intervals

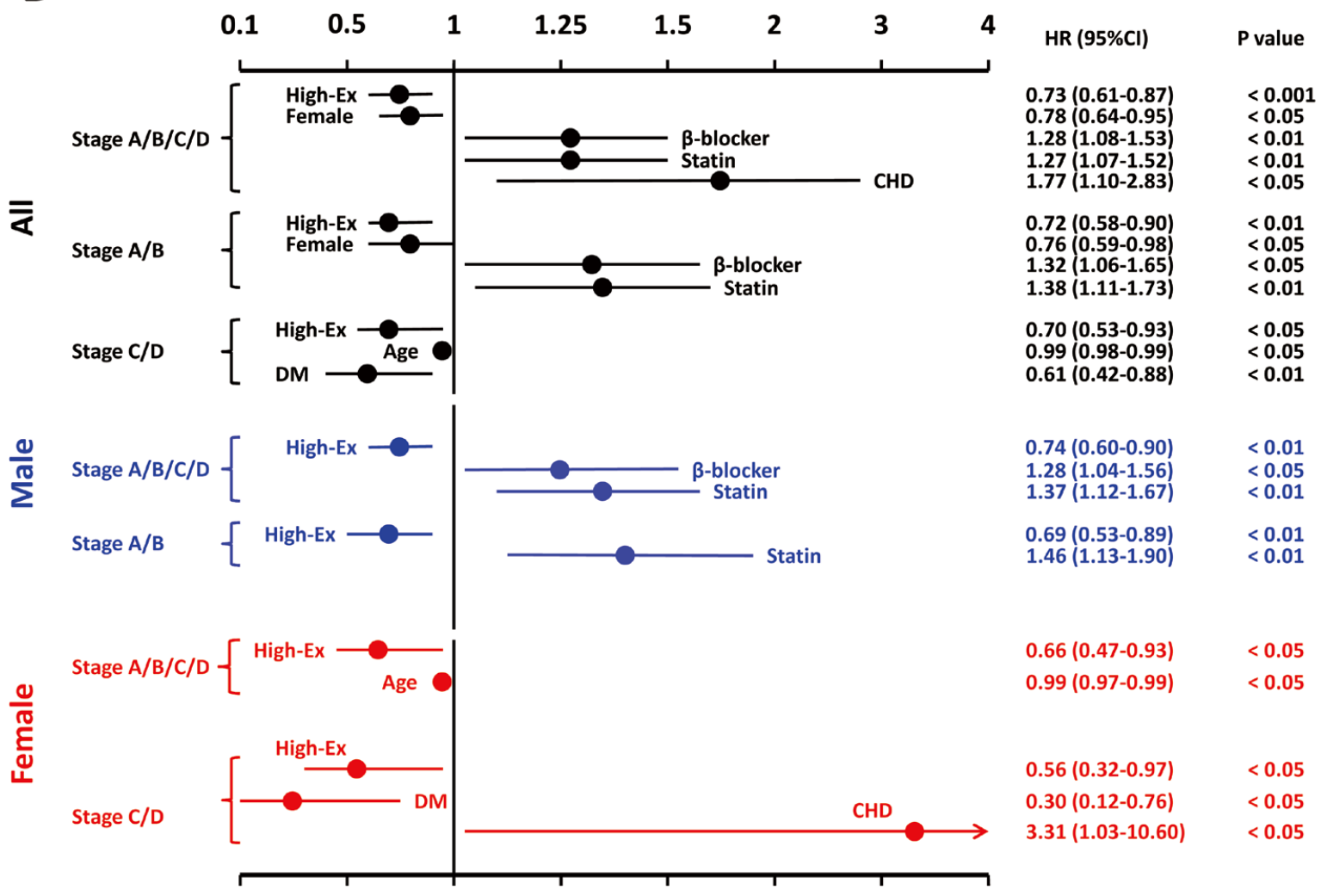

Figure 3. Baseline physical activity level and other cardiovascular events. The high-exercise group (High-Ex) showed better prognosis for other cardiovascular events (except acute myocardial infarction, stroke, and HF hospitalization) in all patients (A), as well as in stage A/B (B) and stage C/D (C) patients. Multivariate analyses also demonstrated a significant correlation between baseline physical activity level and other cardiovascular events in all patients in stages A/B and C/D (D). CHD, congenital heart disease; DM, diabetes mellitus. 


\section{HF Hospitalization}
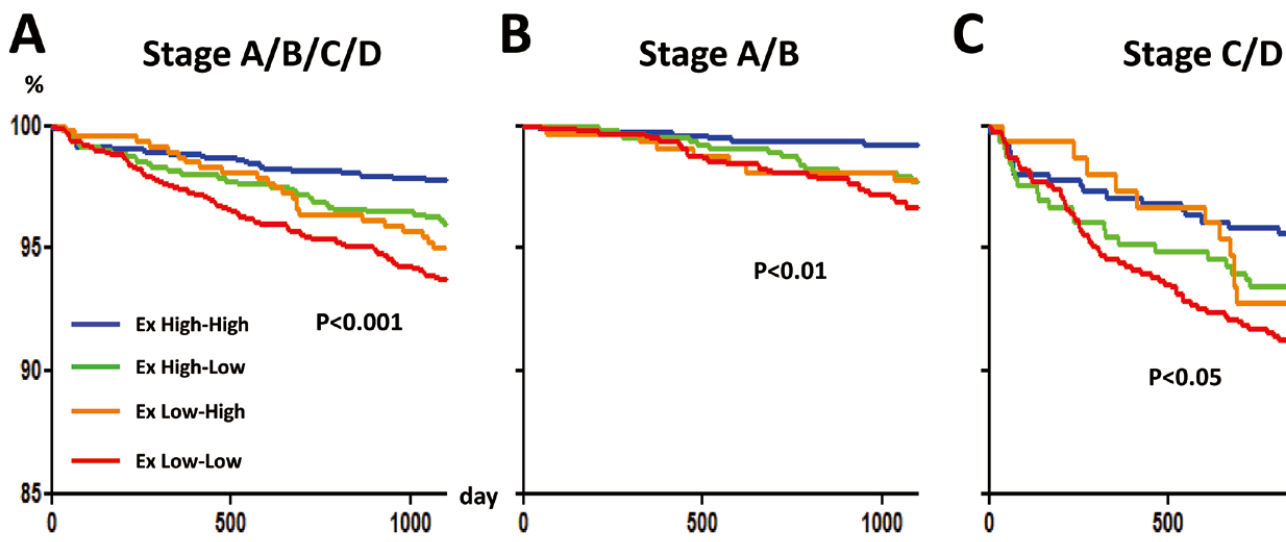

No. at risk

\begin{tabular}{|c|c|c|c|c|c|c|c|c|c|c|c|c|c|c|c|}
\hline Ex High-High & 1,219 & 1,209 & 1,204 & 1,198 & 1,012 & 809 & 808 & 807 & 805 & 677 & 410 & 402 & 398 & 394 & 335 \\
\hline Ex High-Low & 972 & 959 & 951 & 942 & 815 & 638 & 638 & 634 & 631 & 545 & 334 & 322 & 318 & 312 & 270 \\
\hline Ex Low-High & 473 & 471 & 465 & 456 & 399 & 321 & 321 & 318 & 315 & 275 & 152 & 151 & 148 & 142 & 124 \\
\hline Ex Low-Low & 1,687 & 1,657 & 1,630 & 1,609 & 1,390 & 988 & 986 & 976 & 968 & 828 & 699 & 672 & 655 & 642 & 562 \\
\hline
\end{tabular}

\section{Kaplan-Meier Estimate}

D

\section{Cox Hazard Ratio and 95\% Confidence Intervals}

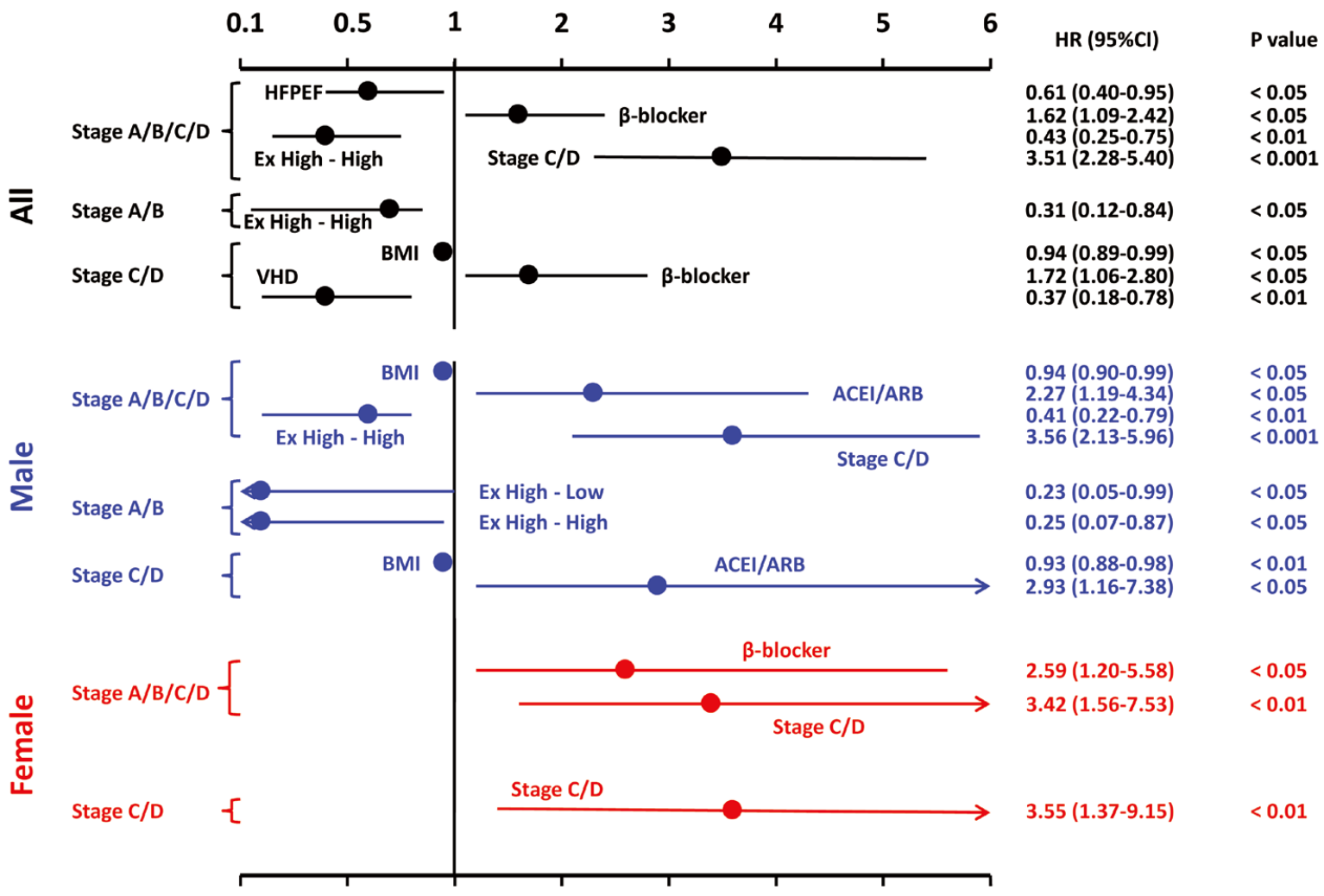

Figure 4. Yearly change in physical activity level and admission for worsening heart failure (HF). Yearly change in physical activity level was significantly associated with admission for worsening HF in all patients (A), as well as in stage $A / B(B)$ and stage $C / D$ (C) patients. Multivariate analyses showed that high-exercise level (High-Ex) was significantly associated with better prognosis for male patients in stage A/B (D). ACEl, angiotensin-converting enzyme inhibitor; ARB, angiotensin-receptor blocker; BMI, body mass index; VHD, valvular heart disease. 


\section{Other Cardiovascular Events}

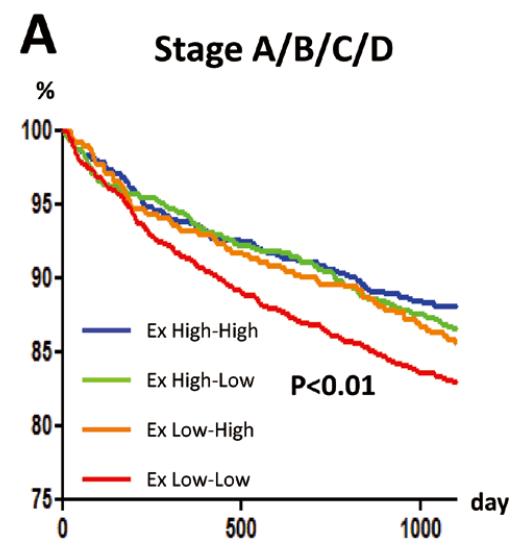

B Stage A/B

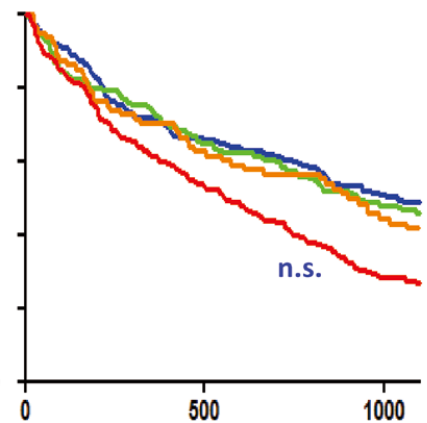

C Stage C/D

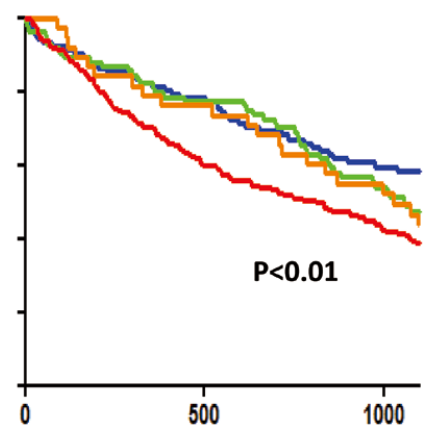

No. at risk

\begin{tabular}{|c|c|c|c|c|c|c|c|c|c|c|c|c|c|c|c|}
\hline Ex High-High & 1,214 & 1,151 & 1,124 & 1,100 & 915 & 807 & 759 & 739 & 727 & 597 & 407 & 393 & 386 & 374 & 318 \\
\hline Ex High-Low & 970 & 928 & 896 & 877 & 735 & 635 & 603 & 580 & 569 & 483 & 335 & 325 & 317 & 310 & 252 \\
\hline Ex Low-High & 472 & 446 & 434 & 423 & 359 & 321 & 321 & 292 & 286 & 239 & 151 & 146 & 143 & 138 & 120 \\
\hline Ex Low-Low & 1,686 & 1,566 & 1,501 & 1,451 & 1,233 & 986 & 909 & 871 & 837 & 698 & 700 & 658 & 631 & 615 & 535 \\
\hline
\end{tabular}

Kaplan-Meier Estimate

D Cox Hazard Ratio and 95\% Confidence Intervals

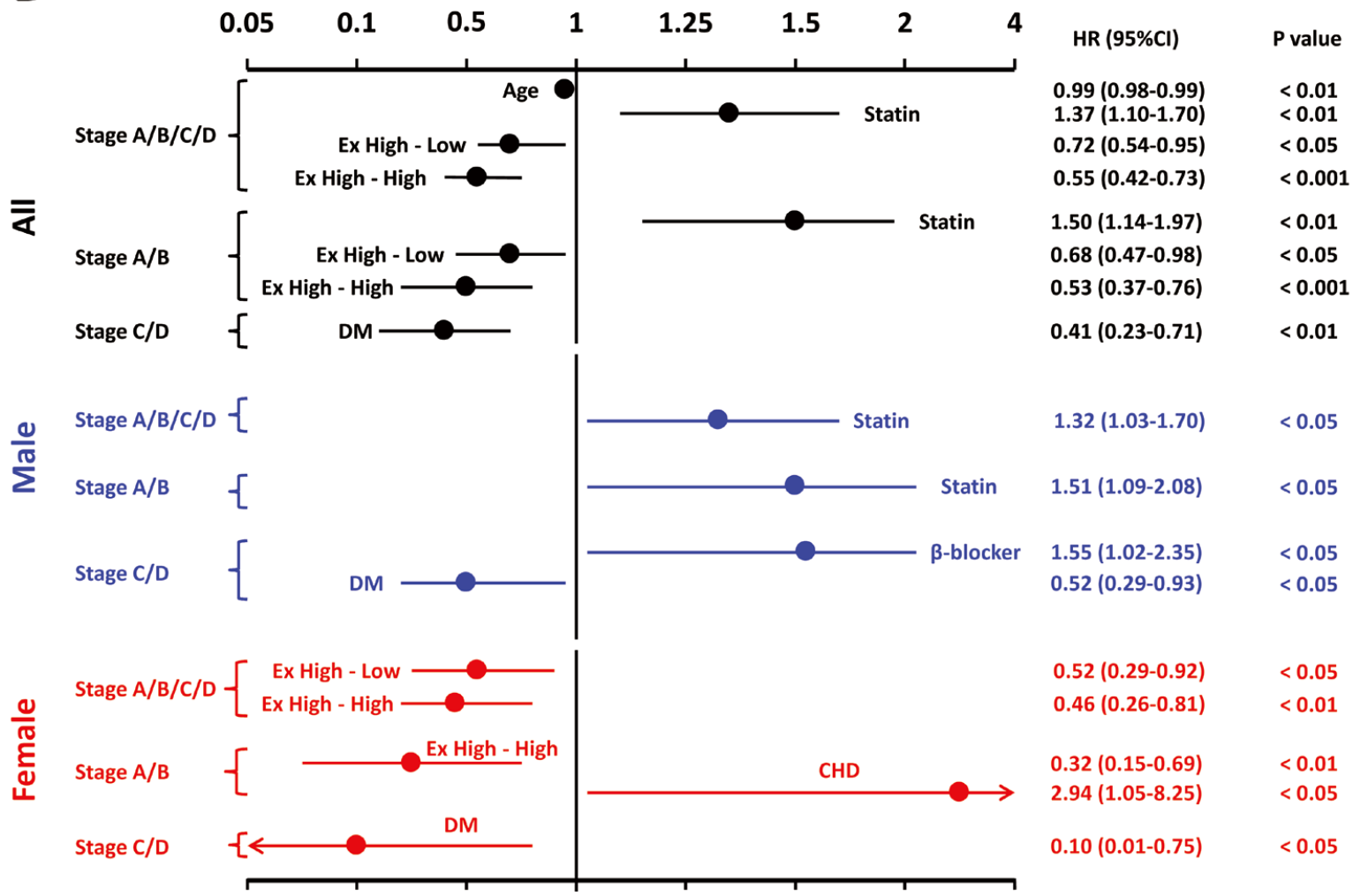

Figure 5. Yearly change in physical activity level and other cardiovascular events. Yearly change in physical activity was significantly associated with other cardiovascular events (except acute myocardial infarction, stroke, and HF hospitalization) in all patients (A), as well as in stage A/B (B) and stage $C / D(C)$ patients. Multivariate analyses showed that high level of physical activity (High-Ex) was significantly associated with better prognosis for female patients in stages $A / B$ and $C / D(D)$. CHD, congenital heart disease; DM, diabetes mellitus; HF, heart failure. 
(Table S4) and in 410 (26\%) of those in stage C/D (Table S5); younger patients in the early stages of CHF tended to maintain higher levels of physical activity (Tables S4,S5).

\section{Yearly Change in Physical Activity Level and Cardiovascular Events During Follow-up}

We subdivided the patients into 4 groups according to their baseline and follow-up physical activity levels as "low to low (n=988)", "low to high (n=321)", "high to low $(\mathrm{n}=638)$ " and "high to high (n=809)" (Table S4). Among the 4 groups, survival free from CHF hospitalization was best in the "high to high" group and was worst in the "low to low" group in both stage $\mathrm{A} / \mathrm{B}$ and $\mathrm{C} / \mathrm{D}$ (Figures $4 \mathrm{~A}-\mathrm{D}$ ). In stage $\mathrm{A} / \mathrm{B}$ patients, survival free from CHF hospitalization in the "high to low" and "low to high" groups was between that in the "high to high" and "low to low" groups, suggesting that physical activity level was well associated with CHF hospitalization (Figure 4B).

Furthermore, other cardiovascular events (except AMI, stroke, and HF hospitalization) were well associated with yearly change in physical activity level in both stage $A / B$ and $C / D$ (Figures 5A-D). Survival free from other cardiovascular events was best in the "high to high" group and worst in the "low to low" group in both stage $\mathrm{A} / \mathrm{B}$ and $\mathrm{C} / \mathrm{D}$ (Figures 5A-D). In female patients especially, high physical activity was associated with other cardiovascular events (Figure 5D).

In contrast, although a yearly change in physical activity was significantly associated with the occurence of AMI, its impact was small (Figures S2A-D). In stages A-D, the occurrence of AMI was comparable between the "high to high" and "high to low" groups, as in the case of "low to high" and "low to low" groups (Figure S2A). In stage C/D, only "low to low" tended to be worst for AMI (Figure S2C).

The impact of a yearly change in physical activity on stroke was also small (Figures S4A-C). Multivariate analyses indicated that "high to high" was the only significant predictor of the occurrence of stroke in stages A-D (Figure S4D).

\section{Discussion}

The novel findings of the present study were that (a) the baseline physical activity level was significantly associated with all-cause death, HF hospitalization and other cardiovascular events (except AMI, stroke and HF hospitalization) and (b) a yearly change in physical activity level was also significantly associated with $\mathrm{HF}$ hospitalization and cardiovascular events during the 3-year follow-up in both stage $\mathrm{A} / \mathrm{B}$ and $\mathrm{C} / \mathrm{D}$ patients. To the best of our knowledge, this is the first study to demonstrate that physical activity is associated with cardiovascular events in CHF patients.

\section{Influence of Baseline Physical Activity Level on Cardiovascular Events and Mortality}

In the present study, the high-exercise group was characterized by younger age and less advanced CHF stage compared with the low-exercise group in both stage $\mathrm{A} / \mathrm{B}$ and $\mathrm{C} / \mathrm{D}$, whereas no significant difference in BNP level was noted between the 2 groups. Because physical activity level and CHF stage are closely linked, it is difficult to simply dissect the effects of physical activity on CHF stage. However, the present study suggests that physical activity is an important therapeutic target for CHF patients.

It has been demonstrated that exercise training is associated with significant reductions in mortality, HF hospitalization, health status and depressive symptoms, as well as improvement of endothelial function in CHF patients. ${ }^{12-16}$ Furthermore, regular physical activity and aerobic exercise training are associated with reduced risk of fatal and nonfatal coronary events as primary and secondary prevention in a wide range of ages..$^{17,18}$ Consistently, the present study demonstrated that a higher level of physical exercise was associated with reductions in all-cause mortality, HF hospitalization, acute coronary syndrome and other cardiovascular events in HF patients in both stage $\mathrm{A} / \mathrm{B}$ and $\mathrm{C} / \mathrm{D}$.

\section{Yearly Change in Physical Activity Level}

Only a few studies have previously examined yearly change in physical activity. In children, physical activity is known to decrease with age, depending on the length of morning school breaks and the issue of road safety in the maintenance of moderate and vigorous activities. ${ }^{19}$ Also in adults, the CPS II Nutrition Cohort, a prospective study of cancer incidence and mortality in the USA, reported that in half of the participants the level of physical activity declined over 10 years. ${ }^{20}$ WHAS II, another prospective cohort study with 436 women aged 70-79 years, who were representative of the two-thirds highest functioning women living in the community, also demonstrated that the prevalence of maintaining a high-exercise level accounted for only $16.6 \%,{ }^{21}$ a consistent finding with the present study ("high to high" group accounted for $28.0 \%$ ). Furthermore, the present study demonstrated that most of the patients with CHF (both stage $\mathrm{A} / \mathrm{B}$ and $\mathrm{C} / \mathrm{D}$ ) decreased their level of physical activity over 3 years, which was associated with various cardiovascular events. To prevent this decline, it is important in future studies to clarify the factors that prevent physical activity in CHF patients.

It has been reported that LV systolic dyssynchrony predicts impaired physical activity level, independently of history of previous MI or regional wall motion abnormality in patients with IHD. ${ }^{22}$ In both stage A/B and C/D, the "high to high" group was characterized by younger age and high baseline level of physical activity. Additionally, the prevalence of valvular heart disease in stage $\mathrm{A} / \mathrm{B}$ and the use of statins in stage $\mathrm{C} / \mathrm{D}$ were significantly associated with the yearly change in physical activity level, although the clinical significance of these findings remains to be examined in future studies.

\section{Change in Physical Activity Level and Cardiovascular Events}

Few studies have examined the influence of changes in physical activity on cardiovascular events in adults. In the WHAS II study, there was a stepwise association between decreased level of physical activity and increased risk of mortality in old women..$^{21}$ The present study also demonstrated that decreased physical activity was associated with increased risk of mortality, HF hospitalization and other cardiovascular events (except AMI, stroke, and HF hospitalization) in male and female patients with $\mathrm{CHF}$ in both stage $\mathrm{A} / \mathrm{B}$ and $\mathrm{C} / \mathrm{D}$, supporting the notion that exercise training is associated with significant reductions in mortality, HF hospitalization and atherosclerosis development. ${ }^{12,17}$

\section{Study Limitations}

First, in the present study, physical activity level was evaluated only by subjective questionnaire not by objective method, which might have caused overestimation of the level. Evaluation of physical activity by objective methods is needed in future studies. Second, in order to evaluate the yearly change in physical activity, we simply divided the patients by the median value of physical activity. Again, evaluation of the yearly change in physical activity by objective methods is needed in future studies. Third, although we were able to obtain data for a relatively large number of CHF patients, some were lacking. 
Fourth, we were unable to clarify the factors that prevented physical activity by CHF patients or to clarify whether a decrease in physical activity was a cause or a result of cardiovascular diseases. Fifth, in some groups, the use of drugs, such as ACEI/ARB or $\beta$-blocker, which are usually recognized as protective agents for $\mathrm{HF}$, was rather associated with worsening of $\mathrm{HF}$, probably because these agents were administered to patients with severe HF. We are currently performing a clinical study to address this issue.

\section{Conclusions}

The present study demonstrates that the baseline and yearly change in physical activity level are associated with all-cause death and HF hospitalization, suggesting that physical activity could be an important therapeutic target to improve the prognosis of CHF patients.

\section{Acknowledgments}

This work was supported by the grants-in-aid from the Japanese Ministry of Health, Labor, and Welfare, Tokyo, Japan (18190401, 21170901, 24120301). We thank the members of the Tohoku Heart Failure Association for their contribution and E. Ishida for excellent technical assistance.

\section{Disclosures}

None.

\section{References}

1. Matsushita $Y$, Takahashi $Y$, Mizoue T, Inoue M, Noda M, Tsugane S. Overweight and obesity trends among Japanese adults: A 10-year follow-up of the JPHC study. Int J Obes (Lond) 2008; 32: 1861-1867.

2. Miura Y, Fukumoto Y, Shiba N, Miura T, Shimada K, Iwama Y, et al. Prevalence and clinical implication of metabolic syndrome in chronic heart failure. Circ J 2010; 74: 2612-2621.

3. Kitzman DW, Little WC, Brubaker PH, Anderson RT, Hundley WG, Marburger CT, et al. Pathophysiological characterization of isolated diastolic heart failure in comparison to systolic heart failure. JAMA 2002; 288: 2144-2150.

4. Redfield MM, Jacobsen SJ, Burnett JC Jr, Mahoney DW, Bailey KR, Rodeheffer RJ. Burden of systolic and diastolic ventricular dysfunction in the community: Appreciating the scope of the heart failure epidemic. JAMA 2003; 289: 194-202.

5. Aoki T, Fukumoto Y, Sugimura K, Oikawa M, Satoh K, Nakano M, et al. Prognostic impact of myocardial interstitial fibrosis in nonischemic heart failure. Circ J 2011; 75: 2605-2613.

6. Tatebe S, Fukumoto Y, Sugimura K, Miyamichi-Yamamoto S, Aoki $\mathrm{T}$, Miura Y, et al. Clinical significance of reactive post-capillary pulmonary hypertension in patients with left heart disease. Circ J 2012; 76: $1235-1244$.

7. Miura M, Shiba N, Nochioka K, Takada T, Takahashi J, Kohno H, et al. Urinary albumin excretion in heart failure with preserved ejection fraction: An interim analysis of the CHART 2 study. Eur $J$ Heart Fail 2012; 14: 367-376.

8. Shiba N, Shimokawa H. Prospective care of heart failure in Japan: Lessons from CHART studies. EPMA J 2011; 2: 425-438.

9. Hunt SA, Abraham WT, Chin MH, Feldman AM, Francis GS, Ganiats TG, et al. 2009 focused update incorporated into the ACC/AHA 2005 guidelines for the diagnosis and management of heart failure in adults: A report of the American College of Cardiology Foundation/ American Heart Association Task Force on practice guidelines: Developed in collaboration with the International Society for Heart and Lung Transplantation. Circulation 2009; 119: e391-e479.

10. Haskell WL, Lee IM, Pate RR, Powell KE, Blair SN, Franklin BA, et al. Physical activity and public health: Updated recommendation for adults from the American College of Sports Medicine and the American Heart Association. Circulation 2007; 116: 1081-1093.

11. Paulus WJ, Tschope C, Sanderson JE, Rusconi C, Flachskampf FA, Rademakers FE, et al. How to diagnose diastolic heart failure: A consensus statement on the diagnosis of heart failure with normal left ventricular ejection fraction by the Heart Failure and Echocardiog- raphy Associations of the European Society of Cardiology. Eur Heart J 2007; 28: 2539-2550.

12. O'Connor CM, Whellan DJ, Lee KL, Keteyian SJ, Cooper LS, Ellis SJ, et al. Efficacy and safety of exercise training in patients with chronic heart failure: HF-ACTION randomized controlled trial. JAMA 2009; 301: 1439-1450.

13. Flynn KE, Pina IL, Whellan DJ, Lin L, Blumenthal JA, Ellis SJ, et al. Effects of exercise training on health status in patients with chronic heart failure: HF-ACTION randomized controlled trial. JAMA 2009; 301: $1451-1459$.

14. Blumenthal JA, Babyak MA, O'Connor C, Keteyian S, Landzberg $\mathrm{J}$, Howlett $\mathrm{J}$, et al. Effects of exercise training on depressive symptoms in patients with chronic heart failure: The HF-ACTION randomized trial. JAMA 2012; 308: 465-474.

15. Ozasa N, Morimoto T, Bao B, Shioi T, Kimura T. Effects of machineassisted cycling on exercise capacity and endothelial function in elderly patients with heart failure. Circ J 2012; 76: 1889-1894.

16. Ohuchi H, Ono S, Tanabe Y, Fujimoto K, Yagi H, Sakaguchi H, et al. Long-term serial aerobic exercise capacity and hemodynamic properties in clinically and hemodynamically good, "excellent", Fontan survivors. Circ J 2012; 76: 195-203.

17. Perk J, De Backer G, Gohlke H, Graham I, Reiner Z, Verschuren M, et al. European guidelines on cardiovascular disease prevention in clinical practice (version 2012): The fifth Joint Task Force of the European Society of Cardiology and other societies on cardiovascular disease prevention in clinical practice (constituted by representatives of nine societies and by invited experts). Developed with the special contribution of the European Association for Cardiovascular Prevention \& Rehabilitation (EACPR). Eur Heart J 2012; 33: 1635-1701.

18. Swift DL, Lavie CJ, Johannsen NM, Arena R, Earnest CP, O'Keefe $\mathrm{JH}$, et al. Physical activity, cardiorespiratory fitness, and exercise training in primary and secondary coronary prevention. Circ J 2013; 77: $281-292$.

19. Mantjes JA, Jones AP, Corder K, Jones NR, Harrison F, Griffin SJ, et al. School related factors and $1 \mathrm{yr}$ change in physical activity amongst 9-11 year old English schoolchildren. Int J Behav Nutr Phys Act 2012; 9: 153.

20. Wolin KY, Fagin C, Ufere N, Tuchman H, Bennett GG. Physical activity in US blacks: A systematic review and critical examination of self-report instruments. Int J Behav Nutr Phys Act 2010; 7: 73 .

21. Xue QL, Bandeen-Roche K, Mielenz TJ, Seplaki CL, Szanton SL, Thorpe RJ, et al. Patterns of 12-year change in physical activity levels in community-dwelling older women: Can modest levels of physical activity help older women live longer? Am J Epidemiol 2012; 176: $534-543$.

22. Wang M, Yan GH, Yue WS, Siu CW, Yiu KH, Lee SW, et al. Left ventricular mechanical dyssynchrony impairs exercise capacity in patients with coronary artery disease with preserved left ventricular systolic function and a QRS duration $\leq 120 \mathrm{~ms}$. Circ J 2012; 76: 682-688.

\section{Supplementary Files}

Supplementary File 1

Figure S1. Baseline physical activity level and the occurrence of acute myocardial infarction.

Figure S2. Yearly change in physical activity level and the occurrence of acute myocardial infarction.

Figure S3. Baseline physical activity level and the occurrence of stroke.

Figure S4. Yearly change in physical activity level and the occurrence of stroke.

Table S1. Physical activity questionnaire

Table S2. Baseline characteristics of CHF patients with low and high physical activity levels (stages A/B/C/D)

Table S3. Baseline characteristics of CHF patients with yearly changes in physical activity level during 3-year follow-up (stages A/B/C/D)

Table S4. Baseline characteristics of stage A/B CHF patients categorized by yearly change in physical activity level during 3-year follow-up

Table S5. Baseline characteristics of stage C/D CHF patients categorized by yearly change in physical activity level during 3-year follow-up

Please find supplementary file(s);

http://dx.doi.org/10.1253/circj.CJ-13-0746 